\title{
Inversion of Farmland Soil Moisture in Large Region Based on Modified Vegetation Index
}

\author{
J. X. Wang ${ }^{1}$, B. S. Yu ${ }^{1}$, G. Z. Zhang ${ }^{2,3 *}$, G. C. Zhao ${ }^{1}$, S. D. He ${ }^{1}$, W. R. Luo ${ }^{1}$, C. C. Zhang ${ }^{1}$ \\ 1. School of Water Conservancy \& Environment of Zhengzhou University, Zhengzhou 450001, China (Wang, Yu, Zhao, He, \\ Luo, Zhang) - jxwang@zzu.edu.cn \\ 2. CMA • Henan Key Laboratory of Agrometeorological Support and Applied Technique, Zhengzhou, 450003, China - \\ hnzgz@163.com \\ 3. Henan Institute of Meteorological Sciences, Zhengzhou 450003, China
}

KEY WORDS: Soil Moisture, Normalized Difference Vegetation Index, Modified Vegetation Index, Henan Province China, Winter Wheat

\begin{abstract}
:
Soil moisture is an important parameter for agricultural production. Efficient and accurate monitoring of soil moisture is an important link to ensure the safety of agricultural production. Remote sensing technology has been widely used in agricultural moisture monitoring because of its timeliness, cyclicality, dynamic tracking of changes in things, easy access to data, and extensive monitoring. Vegetation index and surface temperature are important parameters for moisture monitoring. Based on NDVI, this paper introduces land surface temperature and average temperature for optimization. This article takes the soil moisture in winter wheat growing area in Henan Province as the research object, dividing Henan Province into three main regions producing winter wheat and dividing the growth period of winter wheat into the early, middle and late stages on the basis of phenological characteristics and regional characteristics. Introducing appropriate correction factor during the corresponding growth period of winter wheat, correcting the vegetation index in the corresponding area, this paper establishes regression models of soil moisture on NDVI and soil moisture on modified NDVI based on correlation analysis and compare models. It shows that modified NDVI is more suitable as a indicator of soil moisture because of the better correlation between soil moisture and modified NDVI and the higher prediction accuracy of the regression model of soil moisture on modified NDVI. The research in this paper has certain reference value for winter wheat farmland management and decision-making.
\end{abstract}

\section{INTRODUCTION}

Soil moisture is the condition of water content of soil, affecting the physical properties of soil, related to the process of dissolution and conversion of various organics and inorganics in soil. It is an important index in the fields of hydrology, agricultural science, etc. Accurate monitoring of soil moisture can guide agricultural activities scientifically and is of great significance. Ground-based observation and remote sensing are the two primary means of monitoring soil moisture. Groundbased observation is accurate in real time but costly, the discrete data obtained by it is difficult to express large areas of continuous soil moisture. Remote sensing can perform largescale synchronous observations quickly and periodically and can dynamically track changes in things (Zhang, 2008). The development of remote sensing technology compensates for the disadvantages of ground observation technology such as high cost, low space coverage, and observation lag to a certain extent Remote sensing monitoring of soil moisture can be divided into two major categories, one is based on changes in soil moisture that can cause changes in the spectral reflectance of the soil, the other is based on the fact that drought can cause changes in the physiological processes of plants, altering the spectral properties of the leaves, and thus significantly affecting the spectral reflectance of the crown (Liu et al., 2003a). The soil moisture monitoring based on vegetation index belongs to the above-mentioned second category. Domestic and foreign researchers have been established normalized difference vegetation index, anomaly vegetation index, conditional vegetation index, etc., that be used to monitor soil moisture.
These indexes have a good effect on monitoring the relative soil moisture at large-scale and regional levels during the year (Chen, 2013). After years of research, remote sensing monitoring of soil moisture has reached some basic consensus: 1) The remote sensing monitoring of soil moisture is best around $10 \mathrm{~cm}-20 \mathrm{~cm}$ soil (Liu et al., 2003a, Wu et al., 2014a, Chen et al., 1999a, Zhang et al.,2012a), and the correlation between soil moisture of surface and deep and remote sensing data is often poor (Chen et al., 1999a) ; 2) Bare soil and low vegetation are best with thermal inertial model and microwave remote sensing (Chen et al., 1999a, Yan et al., 2006a, Zhang et al., 2007a) ; the complete vegetation coverage with crop water stress index (CWSI), anomaly vegetation index, conditional vegetation index, feature space model, energy index, and vegetation water supply index are better (Liu et al., 2003a, Wu et al., 2014a, Chen et al., 1999a, Wang et al., 2007a); the partial vegetation coverage with farmland evapotranspiration model (but the model is complex), the improved thermal inertial model and the temperature adjustment index are better ${ }^{[5,8]}$.In short, when the bare soil, the thermal properties of the soil play a decisive role, and the method based on temperature is better. When the vegetation is dense, the growth status of the vegetation is an important indicator, and the exponential method is dominant; when the half of the vegetation cover, taking into account the dual effects of differences in soil and vegetation thermal characteristics, the composite index or method is best. It has been fully demonstrated that surface temperature and vegetation index are the main indicators in optical remote sensing monitoring of agricultural moisture (Yan et al., 2006a).Currently, the way remote sensing monitoring of

\footnotetext{
* Corresponding author
} 
soil moisture is inseparable from the test and support of the surface moisture measured data. Due to the uncertainty, variability and complexity of the land surface and its coverage, the method extracting soil moisture by remote sensing is very limited in the accuracy, and there is still a small distance from the actual application. Studies have shown that each method has its own characteristics and applicable conditions. Due to the complexity of surface ecology, there is no universal moisture index and method. The actual application should be based on the characteristics of the specific research object, introduced relevant factors in the general methods that should be reasonably modified and improved, and make the application effects improve to some extent. This article takes the soil moisture in the main producing area of winter wheat in the Huang-Huai-Hai Plain of central and eastern Henan Province as the research object. Based on the NDVI, the corresponding factors in different regions and at different growth stages are introduced into the improvement, and the corrected vegetation index was obtained. This paper establishes regression models of soil moisture on NDVI and soil moisture on modified NDVI based on correlation analysis, and achieves effective monitoring of farmland moisture.

\section{OVERVIEW OF THE RESEARCH AREA AND DATA SOURCES}

\subsection{Overview of the Research Area}

Huang-Huai-Hai Plain of Henan Province is located between latitude $32^{\circ} 08^{\prime}-36^{\circ} 21^{\prime} \mathrm{N}$ and longitude $112^{\circ} 51^{\prime}-116^{\circ} 35^{\prime} \mathrm{E}$, the trend of terrain is high in the west and low in the east, west from the $100 \mathrm{~m}$ elevation contour and the hilly edge of northwestern Henan, east to the boundary of Henan and Shandong and the boundary of Henan and Anhui, north from the boundary of Henan and Hebei, south to the Huaihe River, the area of it is about $87000 \mathrm{~km}^{2}$, is $52.4 \%$ of Henan's total area. From north to south it spans three major river basins: the Haihe River, the Yellow River, and the Huaihe River. Located in the warm temperate zone and the north subtropics, it belongs to a humid to semi-humid monsoon climate. The annual average temperature is between $12^{\circ} \mathrm{C}$ and $16^{\circ} \mathrm{C}$ The annual temperature range and the daily temperature range are large. The annual frost-free period is approximately 180-240 days from north to south. The annual average precipitation is $500-900 \mathrm{~mm}$, and affected by the monsoon, the temporal and spatial distribution of annual precipitation is uneven, gradually increasing from north to south. The precipitation in the whole year is mainly concentrated in summer, accounting for about half of the annual precipitation, and little precipitation in winter. The annual sunshine hours are $2100-2600 \mathrm{~h}$. The light and heat resources are relatively sufficient, which can basically meet the needs of two crops a year. The average annual surface evaporation is $1300-1600 \mathrm{~mm}$, gradually decreasing from north to south. Influenced by various natural conditions such as climate, geomorphology, and hydrology, there are numerous types of soil, and it is suitable for agricultural development. This area is the main wheat production area in China.

\subsection{Data sources and Data Preprocessing}

The remote sensing data used in this paper includes: Terra MODIS data for the b1, b2 and b7 and MODIS daily land surface temperature product of the 2014-2015 wheat production year in study area, download from the sharing website (https://ladsweb.nascom.nasa.gov/). The data level of the land surface reflectance data $\mathrm{b} 1, \mathrm{~b} 2$, and b7 is L2.The above data has been geometrically corrected and atmospherically corrected. The spatial resolution of the b1 and b2 is $250 \mathrm{~m}$, the spatial resolution of the b7 is $500 \mathrm{~m}$, and the spatial resolution of MODIS daily land surface temperature data is $1000 \mathrm{~m}$. The MODIS daily land surface temperature data includes two data for day and night, averaged here. MODIS source data is Sinusoidal projection, converted to Albers equal-area projection of WGS 84 benchmark by using MRT software. Resampled land surface temperature data and b7 to $250 \mathrm{~m}$ spatial resolution, matched with $\mathrm{b} 1$ and $\mathrm{b} 2$, and performed pixel-level calculations to get NDVI and $b 7 / b 1$.

The soil moisture and other data involved in this study: the soil moisture measurement data for $10 \mathrm{~cm}$ and $20 \mathrm{~cm}$ in the study region in 2014-2015, the monthly average temperature data of multiple monitoring stations in the study area from 1981 to 2010, the regional data of winter wheat planted in Henan Province in 2014-2015 and the administrative boundary data of Henan Province. These data are obtained from the investigation of the Henan Meteorological Bureau. The soil moisture measurement data are the average of $10 \mathrm{~cm}$ and $20 \mathrm{~cm}$ daily soil volumetric moisture content at more than 100 sites in the study area. Among them, there are 29 stations in northern Henan, 59 stations in central Henan, and 15 stations in southern Henan. Interpolated the monthly average temperature for 30 years of each station in the study area by using inverse distance weighting, and get the average monthly temperature for each pixel in each region. The 2014-2015 winter wheat planted areas data and the Henan provincial administrative boundary data are also converted to the same reference benchmark and projection as the above-mentioned remote sensing data. Then cut the image data into the boundary shape. Use ArcGIS software for uniform sampling in three areas, plus the number of measured data, to ensure that the number of samples in each area is more than 100 .

\section{METHODS AND PROCESSES OF THE RESEARCH}

\subsection{Division of the Winter Wheat Growth Area and Period}

In large-scale wheat moisture monitoring, it is necessary to consider the geographical differences, but also to consider the phenological characteristics of winter wheat. The Yellow River and the border between Zhumadian City and Luohe City is an important comprehensive geographical division and wheat ecological zoning boundary in Henan Province (Li, 2010, Mao,

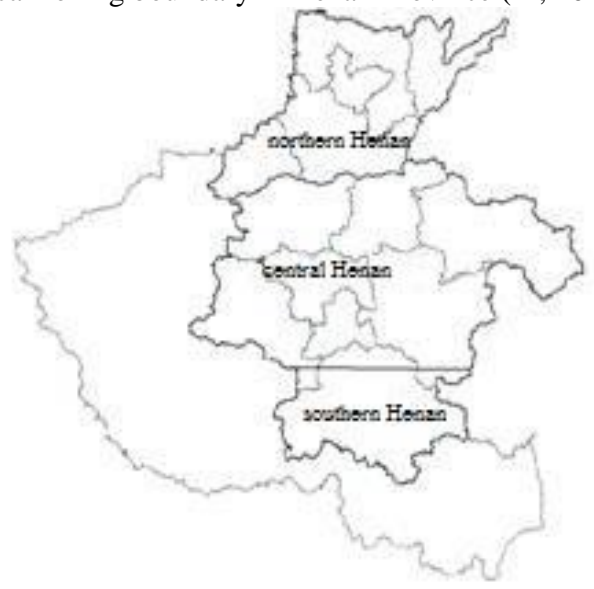

Figure 1. The division of main wheat planted areas in Henan Province 
2011). This paper takes the $33^{\circ} \mathrm{N}$ (the boundary between Zhumadian City and Luohe City) and the Yellow River as the boundary, and divides the winter wheat planted areas in Henan Province into three regions: northern Henan, central Henan and southern Henan. As shown in Figure 1.

The growth cycle of winter wheat in Henan Province lasted for eight months. From October of the first year to June of the following year, the fluctuations in temperature were significant, and the ecological factors affected significantly. The division of the winter wheat growth period is roughly based on the returning green stage and milk stage. Early, from sowing to returning green stage, bare soil to half of the vegetation cover; medium-term, from returning green stage to milk stage, full of vegetation cover; the latter, from milk stage to harvest, the wheat yellowing stage. As shown in Table 1.

\begin{tabular}{lllllll}
\hline & \multicolumn{2}{c}{ Early period } & \multicolumn{2}{c}{ Middle period } & \multicolumn{2}{c}{ Later period } \\
Time & Days & Time & Days & Time & Day \\
\hline $\begin{array}{l}\text { Northern } \\
\text { Henan }\end{array}$ & $10.01-3.11$ & 161 & $3.12-5.19$ & 69 & $5.20-6.18$ & 30 \\
$\begin{array}{l}\text { Central } \\
\text { Henan }\end{array}$ & $10.11-3.01$ & 141 & $3.02-5.14$ & 74 & $5.15-6.08$ & 25 \\
$\begin{array}{l}\text { Southern } \\
\text { Henan }\end{array}$ & $10.21-2.20$ & 123 & $2.21-5.09$ & 77 & $5.10-5.29$ & 20 \\
\hline
\end{tabular}

Table 1. Division of winter wheat growth period in Henan Province research area

\subsection{Theoretical Basis}

Normalized difference vegetation index (NDVI) is a unique spectral signal extracted from the optical parameters of the crown. The indicator obtained by performing specific operations using multi-band information can reflect the growth status of the vegetation to a certain extent (Xiong, 2013), without dimension.

$$
N D V I=\frac{N I R-R}{N I R+R}
$$

Where $\quad$ NDVI $=$ normalized difference vegetation index $\mathrm{NIR}=$ the reflection value in the near infrared band $\mathrm{R}=$ the reflection value in the red band

NDVI values range from -1 to 1 . The ground coverage is cloud, water, snow, etc. The reflection of visible light is strong when the ground coverage is cloud, water, snow, etc., then the vegetation index value is negative. The value of NDVI such as rock or bare soil is 0 . Positive values indicate vegetation coverage. The NDVI in vegetation area ranges from 0.2 to 0.8 . The vegetation index reflects the vegetation growth status and can calculate the soil moisture indirectly. However, when the water supply to the vegetation is insufficient, the changes in the growth status term will not be realized immediately in the short. Therefore, the vegetation index is low sensitive to the water stress index and the time will be delayed (Goetz, 1997a). The delay is also related to the actual situation and cannot reflect the situation of soil moisture in time.

The land surface temperature is also an important parameter to reflect soil moisture. Changes in soil temperature reflect changes in soil moisture. When the water content in the upper layer of the soil decreases, the heat capacity of the soil decreases correspondingly, and the surface temperature increases after receiving solar radiation. The increase of surface temperature of the bare soil is a manifestation of soil drought.
The increase of vegetation canopy temperature is the primary indicator of plant water stress and drought. In order to reduce the loss of water due to transpiration, the plant leaf pores will close, causing a reduction in the surface latent heat flux, which will increase the surface sensible heat flux. The increase in sensible heat flux leads to an increase in canopy temperature (Yan, 2009). The principle of soil moisture monitoring based on land surface temperature is based on the effect of soil moisture on the temperature of the surface (canopy). From the perspective of vegetation physiology, soil water content mainly affected the transpiration and photosynthesis of vegetation. In addition, there are many factors that affect the land surface temperature, especially when the land surface temperature on remote sensing images is usually the temperature of mixed pixels consisting of different features such as soil, vegetation, and buildings.

Therefore, this process using remote sensing information to obtain surface soil water status has errors.

\subsection{The Principle and Method of Revision of NDVI}

In the early growth stage of winter wheat, the wheat seedlings can not completely cover bare soil, NDVI can not reflect the water condition fully, and the soil temperature must be considered. According to the characteristics of the soil, at the same time and under the same conditions of light and heat, if the soil moisture is high, the temperature will decrease; if the soil moisture is low, the temperature will rise. Therefore, considering the dimension of NDVI, the following corrections are made to the NDVI:

$$
E_{N D V I}=N D V I+\frac{\bar{T}-T}{T}
$$

Where $\quad \mathrm{E}_{\mathrm{NDVI}}=$ the modified NDVI in early stage

NDVI = normalized difference vegetation index

$\overline{\mathrm{T}}=$ the multi-year daily average temperature of the area by pixel

$\mathrm{T}=$ the land surface temperature of the day.

Since $\overline{\mathrm{T}}$ and $\mathrm{T}$ cannot be accurately known, the interpolated average monthly temperature for each pixel of the many years measured at the stations in this area and the land surface temperature inversion by remote sensing are used instead.

In the middle period of winter wheat growth, vegetation basically covers the surface, and NDVI reflects the growth status of plants well. However, on the one hand, NDVI is apt to be saturated with lush vegetation, and its value is less than the actual value due to noise and other factors. On the other hand, NDVI will be delayed relative to the changes of soil moisture. According to our research, the delay time is about 4-6 days. Thus, we must correct the NDVI and try to synchronize it with the soil moisture. Since the change in soil moisture is accompanied by a change in land surface temperature, in addition to considering the difference between the soil temperature and the average temperature over the years, it is necessary to introduce the changes between the land surface temperature data of the previous day and the land surface temperature data of the day. In summary, the mid-term revised NDVI is as follows: 


$$
M_{N D V I}=N D V I+\frac{\left(T_{n-1}-T_{n}\right)+\left(\bar{T}-T_{n}\right)}{T_{n}}
$$

Where $\quad \mathrm{M}_{\mathrm{NDVI}}=$ the modified NDVI for the medium term NDVI $=$ normalized difference vegetation index

$\overline{\mathrm{T}}=$ the multi-year daily average temperature of the area by pixel

$\mathrm{T}_{\mathrm{n}}=$ the land surface temperature of the day

$\mathrm{T}_{\mathrm{n}-1}=$ the land surface temperature data of the previous day

The first part of the modification (the first item of the molecule) plays a major role in advancing the hysteresis of NDVI, the role of the latter part (the second part of the molecule) is similar to that of the early period, which is mainly used to improve the saturation of NDVI.

In the later growth stage of winter wheat, the wheat turns yellow and the NDVI becomes smaller, but it does not mean that the soil moisture is low. Therefore, it is also necessary to correct the later NDVI. Based on the water absorption curve and the curve of vegetation and soil reflectivity, Du Xiao et al. proposed that the b6 and b7 (microwave infrared) of MODIS reflect the spectral information of soil and vegetation, and constructed the surface water content index (SWCI) model (Du et al., 2007a). On this basis, Zhang Hongwei et al. considered the absorption of green vegetation chlorophyll to the spectrum, introduced the information of $b 1$, and used $b 1 / b 7$ as a correction factor to construct an enhanced soil surface water content index (ESWCI) model and applied it in the lush vegetation period (Zhang et al., 2012a). The wheat in the middle period is lushest, and in the later stage, the wheat gradually turns yellow and the growth declines. The vegetative feature in later stage is contrary to the above, so the opposite correction factor is cited. In summary, the NDVI in this stage is revised as follows:

$$
L_{N D V I}=N D V I \times \frac{b_{7}}{b_{1}}
$$

Where $\quad \mathrm{L}_{\mathrm{NDVI}}=$ the modified NDVI in the later stage NDVI $=$ normalized difference vegetation index $b_{7}, b_{1}=$ the spectral reflectance of MODIS corresponding band.

\subsection{Research Process}

This study divides the research area into three regions: northern Henan, middle Henan, and southern Henan, and divides the winter wheat growth period in the respective region. Using software such as ENVI and ArcGIS to process the data, calculating the NDVI in winter wheat growing period in the study area from 2014 to 2015 , correcting the vegetation index in the corresponding area, this paper establishes regression models of soil moisture on NDVI and soil moisture on modified NDVI based on correlation analysis. Obtained quadratic regression equation and conducted soil moisture forecasting and accuracy analysis. Finally discuss the results. The following figure shows the technology roadmap.

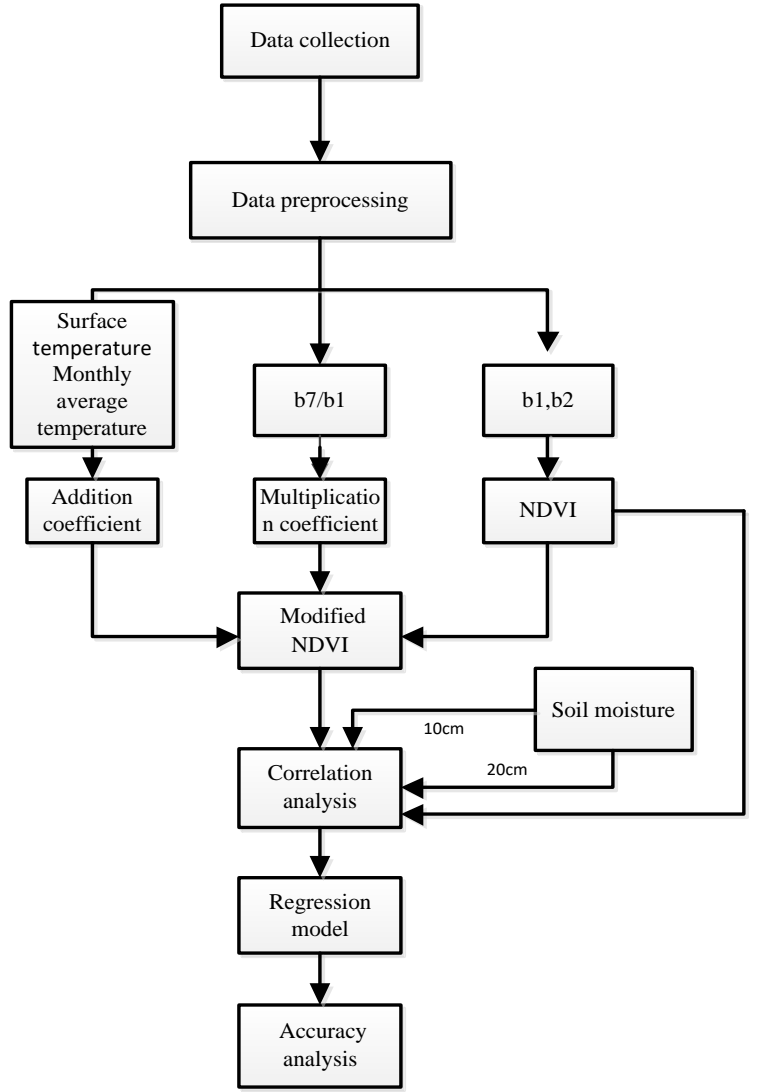

Figure 2. Technology roadmap

\section{RESULTS AND ANALYSIS}

\subsection{Correlation Analysis of NDVI, Modified NDVI and Soil Moisture}

There is a positive correlation between the NDVI and soil moisture. When other conditions are relatively stable, the better the soil moisture is, the lusher the vegetation is. The modified NDVI in this paper is a modification of NDVI based on the characteristics of NDVI and the phenology of wheat. Although there are differences between them in the value range, they are consistent to reflect the nature of the vegetation growth. In other words, there is a positive correlation between the modified NDVI and soil moisture, it should be better in theory.

Table 2 and Table 3 list the correlation between NDVI and soil moisture and the correlation between modified NDVI and soil moisture in early period, middle period and later period in central Henan. From the table, we can see that the correlation between modified NDVI and soil moisture is better. Therefore, it is necessary to make corrections to improve the accuracy of prediction.

\begin{tabular}{ccccccc}
\hline Area & \multicolumn{2}{c}{ Early $(10.25)$} & \multicolumn{2}{c}{ Middle $(3.2)$} & \multicolumn{2}{c}{ Later (5.15) } \\
\hline \multirow{2}{*}{ Central } & NDVI & Modified & NDVI & Modified & NDVI & Modified \\
& NDVI & NDVI & NDI \\
Henan & $0.331 *$ & $0.492 * *$ & $0.446 * *$ & $0.525 * *$ & 0.316 & $0.423 * *$ \\
\hline
\end{tabular}

* Represents a significant correlation at the 0.05 level, ** Represents a significant correlation at the 0.01 level

Table 2. Correlations of NDVI, modified NDVI and soil moisture of $10 \mathrm{~cm}$ in central Henan 


\begin{tabular}{|c|c|c|c|c|c|c|}
\hline \multirow{2}{*}{$\frac{\text { Area }}{\text { Central }}$} & \multicolumn{2}{|c|}{ Early (10.25) } & \multicolumn{2}{|c|}{ Middle (3.2) } & \multicolumn{2}{|c|}{ Later (5.15) } \\
\hline & NDVI & $\begin{array}{c}\text { Modified } \\
\text { NDVI }\end{array}$ & NDVI & $\begin{array}{c}\text { Modified } \\
\text { NDVI }\end{array}$ & NDVI & $\begin{array}{c}\text { Modified } \\
\text { NDVI }\end{array}$ \\
\hline Henan & $0.321 *$ & $0.520 * *$ & 0.259 & 0.302 & $0.365^{*}$ & $0.580 * *$ \\
\hline
\end{tabular}

Table 3. Correlations of NDVI, modified NDVI and soil moisture of $20 \mathrm{~cm}$ in central Henan

\subsection{Regression Analysis of Soil Moisture on NDVI and Modified NDVI}

Based on the correlation analysis, this paper do regression analysis of soil moisture of $10 \mathrm{~cm}$ and $20 \mathrm{~cm}$ on NDVI and modified NDVI. Taking into account the incomplete conditions of ground temperature data, the dates of relatively complete remote sensing ground temperature data in the three regions were selected. The main steps are as follows:

(1) Considering the condition that the land surface temperature data is incomplete, the date with relatively complete data in the three regions is selected.

(2) Entered the raster images in ArcGIS. The attribute information of the images are NDVI, land surface temperature, b7/b1, interpolated soil moisture and monthly average temperature. And input the latitude and longitude data of the samples as the area of interest.

(3) Exported the text information of the samples, the information are NDVI, daily land surface temperature, $b 7 / b 1$, soil moisture of $10 \mathrm{~cm}$ and $20 \mathrm{~cm}$ and monthly average temperature. Then calculate modified NDVI according to the correction formula in EXCEL.

(4) Make $10 \mathrm{~cm}$ soil moisture and NDVI for each date a set of corresponding related variables, make $10 \mathrm{~cm}$ soil moisture and modified NDVI for each date a set of corresponding related variables, and do regression analysis in SPSS. Perform curve estimation and get quadratic modeling, obtain relevant parameters of the model and fitted regression curves. Do the same for $20 \mathrm{~cm}$ soil moisture and NDVI and modified NDVI.

Next show a few regression curves.

Directions : On the left is soil moisture - NDVI regression curve, on the right is soil moisture - modified NDVI regression curve, the abscissa on the left is NDVI, on the right is modified NDVI, both of the ordinate is soil moisture.
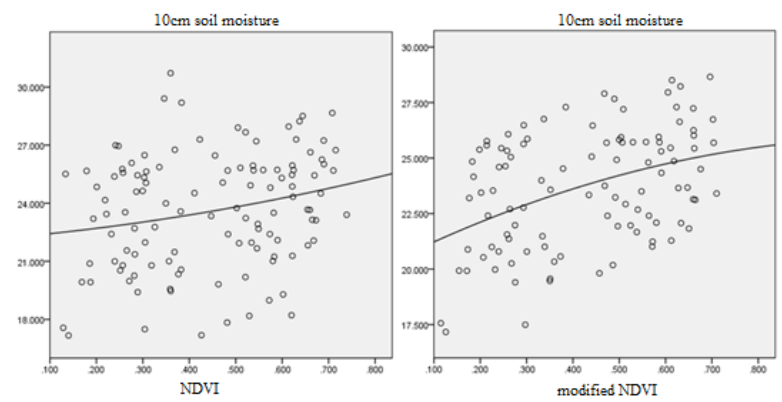

Figure 3. Regression curve of $10 \mathrm{~cm}$ soil moisture on NDVI and modified NDVI in 2.10 in central Henan

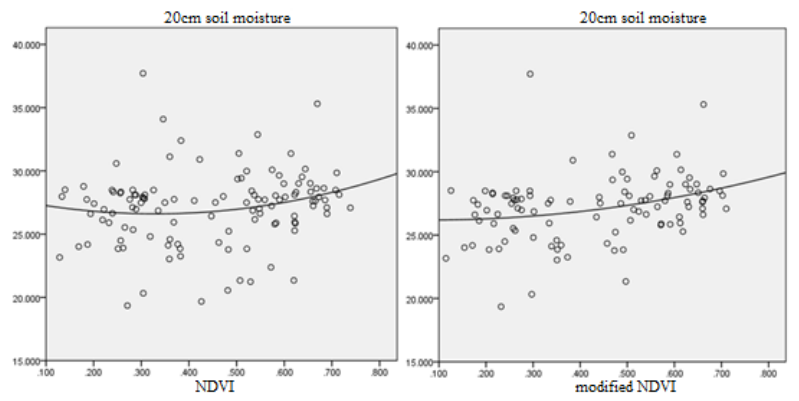

Figure 4. Regression curve of $20 \mathrm{~cm}$ soil moisture on NDVI and modified NDVI in 2.10 in central Henan

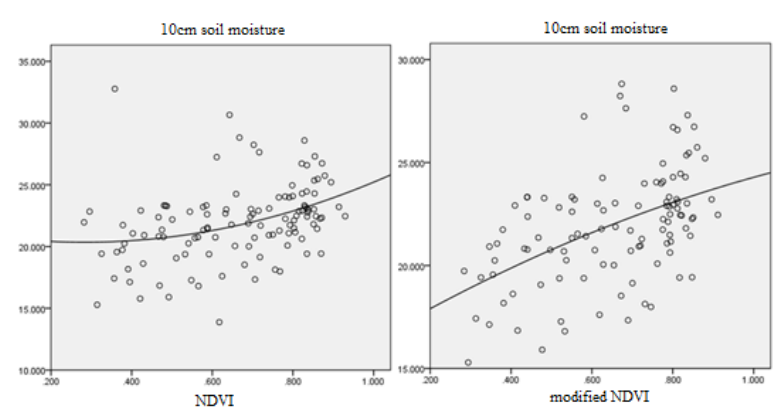

Figure 5. Regression curve of $10 \mathrm{~cm}$ soil moisture on NDVI and modified NDVI in 4.29 in central Henan
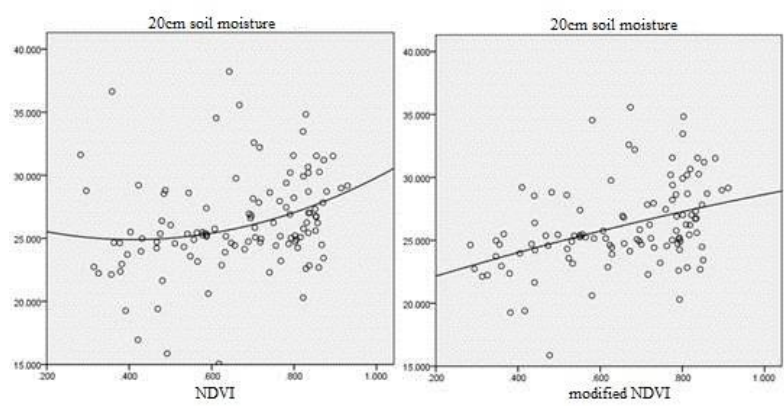

Figure 6. Regression curve of $20 \mathrm{~cm}$ soil moisture on NDVI and modified NDVI in 4.29 in central Henan

The following tables are the regression models of soil moisture on NDVI and soil moisture on modified NDVI in the corresponding early, middle and late periods in northern Henan, central Henan, southern Henan.

\begin{tabular}{lrlccl}
\hline \multicolumn{2}{l}{ Date } & Independent variable & Regression model & $R^{2}$ & $F$ \\
\hline 3.3 & NDVI & $y=-6.29 x^{2}+5.94 x+23.73$ & 0.007 & 0.314 \\
& modified NDVI & $y=-21.63 x^{2}+21.34 x+20.78$ & 0.162 & 7.731 \\
4.29 & NDVI & $y=-15.32 x^{2}+16.86 x+16.97$ & 0.013 & 0.573 \\
& modified NDVI & $y=-10.36 x^{2}+16.48 x+15.97$ & 0.058 & 2.237 \\
5.23 & NDVI & $y=43.91 x^{2}-45.8 x+26.19$ & 0.079 & 3.842 \\
& modified NDVI & $y=12.36 x^{2}-9.27 x+15.4$ & 0.196 & 3.842 \\
\hline
\end{tabular}

Table $4.10 \mathrm{~cm}$ soil moisture regression model in northern Henan 


\begin{tabular}{cccccc}
\hline Date & Independent variable & Regression model & $R^{2}$ & $F$ \\
\hline 3.3 & NDVI & $y=-5.56 x^{2}+4.78 x+27.03$ & 0.002 & 0.079 \\
& modified NDVI & $y=-35.48 x^{2}+32.81 x+21.65$ & 0.157 & 7.448 \\
4.29 & NDVI & $y=-14.44 x^{2}+17.11 x+18.11$ & 0.029 & 1.359 \\
& modified NDVI & $y=-10.11 x^{2}+13.45 x+18.95$ & 0.057 & 2.204 \\
5.23 & NDVI & $y=16.24 x^{2}-14.57 x+21.1$ & 0.062 & 2.968 \\
& modified NDVI & $y=4.57 x^{2}-0.003 x+16.29$ & 0.253 & 9.646 \\
\hline
\end{tabular}

Table $5.20 \mathrm{~cm}$ soil moisture regression model in northern Henan

\begin{tabular}{|c|c|c|c|}
\hline Date & Independent va & Regression model & $R^{2}$ \\
\hline \multirow[t]{2}{*}{2.10} & NDVI & $y=2.27 x^{2}+2.07 x+22.19$ & $0.053 \quad 3.193$ \\
\hline & modified NDVI & $y=-4.64 x^{2}+10.27 x+20.25$ & $0.174 \quad 10.501$ \\
\hline \multirow[t]{2}{*}{4.29} & NDVI & $y=9.47 x^{2}-5.36 x+21.11$ & $0.132 \quad 8.592$ \\
\hline & modified NDVI & $y=-3.14 x^{2}+11.75 x+15.68$ & $0.236 \quad 16.056$ \\
\hline \multirow[t]{2}{*}{5.15} & NDVI & $y=0.18 x^{2}+6.08 x+21.72$ & $0.081 \quad 4.985$ \\
\hline & modified NDVI & $y=-0.67 x^{2}+7.81 x+19.92$ & $0.216 \quad 12.257$ \\
\hline \multicolumn{4}{|c|}{ Table $6.10 \mathrm{~cm}$ soil moisture regression model in central Henan } \\
\hline Date & Independent va & riable $\quad$ Regression model & $R^{2} \quad F$ \\
\hline \multirow[t]{2}{*}{2.10} & NDVI & $y=12.35 x^{2}-8.13 x+27.95$ & $0.034 \quad 1.989$ \\
\hline & nodified NDVI & $y=6.51 x^{2}-1.01 x+26.23$ & $0.092 \quad 5.069$ \\
\hline \multirow[t]{2}{*}{4.29} & NDVI & $y=14.12 x^{2}-11.57 x+27.27$ & 0.0814 .988 \\
\hline & nodified NDVI & $y=-2.07 x^{2}+10.6 x+20.12$ & $0.167 \quad 10.396$ \\
\hline \multirow[t]{2}{*}{5.15} & NDVI & $y=7.28 x^{2}-4.99 x+29.17$ & $0.016 \quad 0.92$ \\
\hline & nodified NDVI & $y=1.17 x^{2}+3.16 x+25.63$ & $0.093 \quad 4.55$ \\
\hline
\end{tabular}

Table $7.20 \mathrm{~cm}$ soil moisture regression model in central Henan

\begin{tabular}{crlrrr}
\hline \multicolumn{2}{c}{ Date } & Independent variable & Regression model & $R^{2}$ & $F$ \\
\hline 1.23 & NDVI & $y=-7.17 x^{2}+3.32 x+23.84$ & 0.052 & 3.392 \\
& modified NDVI & $y=-13.51 x^{2}+10.65 x+21.8$ & 0.042 & 2.245 \\
$4.29 \quad$ NDVI & $y=28.15 x^{2}-32.41 x+26.58$ & 0.081 & 5.417 \\
\multicolumn{2}{c}{ modified NDVI } & $y=17.96 x^{2}-16.51 x+20.76$ & 0.108 & 7.191 \\
5.12 & NDVI & $y=15.88 x^{2}-22.43 x+35.46$ & 0.025 & 1.567 \\
& modified NDVI & $y=-0.27 x^{2}-9.08 x+34.58$ & 0.173 & 11.942 \\
\hline
\end{tabular}

Table $8.10 \mathrm{~cm}$ soil moisture regression model in southern Henan

\begin{tabular}{rclccl}
\hline Date & \multicolumn{2}{l}{ Independent variable } & \multicolumn{1}{c}{ Regression model } & $R^{2}$ & $F$ \\
\hline 1.23 & NDVI & $y=-10.02 x^{2}+6.58 x+26.41$ & 0.078 & 5.171 \\
& modified NDVI & $y=-6.8 x^{2}+2.98 x+27.41$ & 0.099 & 5.67 \\
4.29 & NDVI & $y=13.27 x^{2}-16.9 x+29.5$ & 0.029 & 1.824 \\
& modified NDVI & $y=1.68 x^{2}+0.613 x+23.1$ & 0.039 & 2.381 \\
5.12 & NDVI & $y=1.78 x^{2}-0.8 x+27.57$ & 0.004 & 0.266 \\
& modified NDVI & $y=-3.5 x^{2}+6.81 x+24.84$ & 0.013 & 0.751 \\
\hline
\end{tabular}

Table $9.20 \mathrm{~cm}$ soil moisture regression model in southern Henan

Analyze the model:

(1) Observing each regression curve, it can be found that the sample points generally fall around the regression curve, indicating that there is a curve regression relationship between the samples.

(2) After observing each regression model, we found that the goodness of fit of soil moisture to the modified NDVI regression model was substantially higher than that of soil moisture to the NDVI regression model, suggesting that the correlation between modified NDVI and soil moisture is better, the prediction accuracy of the regression equation of soil moisture to modified NDVI should be better.

(3) Although the goodness of fit of soil moisture to the modified NDVI regression model is generally higher, the goodness of fit of the model is not high. This may be due to the fact that the remote sensing data noise is big and there are fewer sites to be measured, so that the results of the interpolated soil moisture and the monthly average temperature deviate from the actual conditions, resulting in limited fitting accuracy.

(4) In the regression models of northern Henan, central Henan, and southern Henan, the regression model of central Henan generally has the highest degree of goodness of fit, and that of the southern regression model is generally the lowest. The reason for may be related to the number of sites actually measured. The number of sites in central Henan is the largest, the number of sites actually measured in southern Henan is the least, and the more the number of sites, and the results of the interpolated are closer to the true values.

(5) In most regression models, the goodness of fit of $10 \mathrm{~cm}$ soil moisture to NDVI and modified NDVI is higher than $20 \mathrm{~cm}$, which indicates that in this regression model, it is more appropriate to make return of $10 \mathrm{~cm}$ soil moisture.

\subsection{Prediction and Accuracy Analysis of Soil Moisture Based on Regression Model}

Based on the regression model, do the prediction of $10 \mathrm{~cm}$ and $20 \mathrm{~cm}$ soil moisture. The main steps are as follows:

(1) Select proper sites in North Henan, Central Henan, and Southern Henan, and obtain measured soil moisture of $10 \mathrm{~cm}$ and $20 \mathrm{~cm}$ at the site.

(2) Calculate NDVI and Modified NDVI at these points.

(3) According to the regression model, the calculated NDVI and the modified NDVI are assigned to the corresponding regression equations, and predicted soil moisture of the NDVI and the modified NDVI is obtained.

(4) Differences between predicted and actual soil moisture are calculated and standard deviations are calculated for accuracy analysis.

The tables below list the $10 \mathrm{~cm}$ and $20 \mathrm{~cm}$ soil moisture prediction accuracy analysis.

\begin{tabular}{lccc}
\hline Location & Date & $\begin{array}{c}\text { The standard } \\
\text { deviation of the } \\
\text { difference between } \\
\text { NDVI forecasting and } \\
\text { measured moisture }\end{array}$ & $\begin{array}{c}\text { The standard deviation } \\
\text { of the difference } \\
\text { between modified } \\
\text { NDVI forecasting and } \\
\text { measured moisture }\end{array}$ \\
\hline Northern & 3.3 & 3.905 & 3.634 \\
& 4.29 & 6.640 & 6.307 \\
Central & 5.23 & 6.625 & 5.799 \\
& 2.10 & 5.201 & 4.859 \\
Southern & 4.29 & 4.262 & 3.793 \\
& 5.15 & 5.636 & 5.193 \\
& 1.23 & 3.977 & 3.917 \\
& 4.29 & 5.290 & 5.292 \\
& 5.12 & 5.366 & 4.918 \\
\hline
\end{tabular}

Table 10. Accuracy analysis of $10 \mathrm{~cm}$ soil moisture prediction

Analyze the above tables:

(1) In the accuracy analysis, the standard deviation of the difference between the modified NDVI prediction and the actual soil moisture is smaller than it between the NDVI prediction and the actual soil moisture. It shows that the modified NDVI prediction is closer to the actual soil moisture. 


\begin{tabular}{lccc}
\hline Location & Date & $\begin{array}{c}\text { The standard } \\
\text { deviation of the } \\
\text { difference between } \\
\text { NDVI forecasting and } \\
\text { measured moisture }\end{array}$ & $\begin{array}{c}\text { The standard deviation } \\
\text { of the difference } \\
\text { between modified } \\
\text { NDVI forecasting and } \\
\text { measured moisture }\end{array}$ \\
\hline Northern & 3.3 & 5.887 & 3.113 \\
& 4.29 & 3.903 & 3.625 \\
Central & 5.23 & 5.402 & 5.115 \\
& 2.10 & 3.816 & 3.526 \\
Southern & 4.29 & 4.621 & 4.257 \\
& 5.15 & 4.657 & 4.087 \\
& 1.23 & 2.801 & 3.008 \\
& 4.29 & 3.290 & 3.318 \\
\hline
\end{tabular}

Table 11 . Accuracy analysis of $20 \mathrm{~cm}$ soil moisture prediction

In this experiment, it is more appropriate to modified NDVI as an indicator of soil moisture.

(2) Although the standard deviation of the difference between the modified NDVI prediction and the actual soil moisture is smaller, whether NDVI or modified NDVI is used, the standard deviations obtained are relatively large. Analysis of the reasons: First of all, because of various factors, there are more noises in the original remote sensing data, which leads to a less accurate regression model. Secondly, daily land surface temperature products often have loopholes (no index correction at this time), which affects the experimental results. Finally, it may be due to the use of monthly mean temperature instead of daily average annual temperature, as well as the use of daily land surface temperature data instead of true ground temperature data, resulting in the modified NDVI is not accurate enough to deviate from the theoretical value.

(3) There is little difference between the modified NDVI prediction and the NDVI prediction in some days. The reason for may be that the regression model is not accurate enough, the modified NDVI has deviation, the number of measured sites is small and the accidental factors.

\section{CONCLUSIONS AND DISCUSSIONS}

\subsection{Conclusions}

From the result of the study, in general, the regression model of soil moisture on modified NDVI is better than the regression model of soil moisture on NDVI, indicating that modified NDVI in this study area is more suitable as an indicator of soil moisture.

The modified NDVI as an intermediate factor for soil moisture forecasting is an effective method with low cost, wide suitability and good accuracy.

The combination of measured data and remote sensing data can make full use of their complementary advantages and increase the accuracy of soil moisture forecasting.

\subsection{Discussions}

The vegetation index directly reflects the "greenness" index of vegetation growth. As far as crops are concerned, their growth conditions (greenness) are influenced by many factors, including temperature, moisture, sunlight, accumulated temperature, precipitation, soil type and fertility, terrain, field management, crop phenology, planting structure, and so on. Therefore, the vegetation index is a comprehensive reflection of all ecological factors, not only related to temperature and soil moisture. In particular, for large regions, the vegetation index is related to the general trend of temperature and temperature, but it is not the unique and strict highly relevant. The results of this study confirm this point.

Due to many limitations, the measured moisture used in this research is the average value of the day and there is a certain error in the synchronization with the remote sensing images. The current soil moisture monitoring system can already achieve hourly information collection. By reading the shooting time of each remote sensing image, the synchronous error can be controlled for one hour, and it will be more targeted.

\section{ACKNOWLEDGMENTS}

This research is supported by the Open Fund of CMA/Henan Key Laboratory of Agrometeorological Support and Applied Technique in 2014 (Project No. AMF201407) and Henan Science and Technology Project in 2018 (Project No.182102210017).

\section{REFERENCES}

Chen, D. H., 2013. Study on Soil Moisture Inversion Based on MODIS and TM Images. Zhengzhou University.

Chen, H. L., Mao, L. X. and Feng, D. Y., 1999a. A review: theories, methods and development on soil moisture monitoring by remote sensing. Remote Sensing Techology and Application, 14(2), pp. 55-65.

Du, X., Wang, S. X., Zou, Y., Wei, H., 2007a. Construction and validation of a new model for unified surface water capacity based on MODIS data. Geomatics and Information Science of Wuhan University, 32(3), pp. 205-207+211.

Goetz, S. J., 1997a. Multisensor Analysis of NDVI, Surface Temperature and Biophysical Variables at a Mixed Grassland Site. International Journal of Remote Sensing, 18(1), pp. 7194.

Li, Y. W., 2010. Henan Geography. Beijing Normal University Press.

Liu, Z. M., Zhang, B., Yan, M., Li, T. Q., 2003a. Some Research Advances and Trends on Soil Moisture and Drought Monitoring by Remote sensing. Advances in Earth Science, 18(4), pp. 576-583.

Mao, P. F., 2011. Study on Comprehensive Monitoring Index of Winter Wheat Growth Based on Multiple Remote Sensing Parameters. Henan University.

Wang, X., Zhang, Z. X., Zhao, X. L., Tan, W. B., 2007a. A Review of Researchs on Monitoring of Soil Moisture by Remote Sensing. Acta Pedologica Sinica, 44(1), pp. 157-163.

Wu, J. W., Sun, L. Y., Zhang, Y. S., Feng, R., Ji, R. P., Zhang, S. J. and Yu, W. Y., 2014a. Comparative Study on the Methods of Estimating Soil Moisture by Remote Sensing under Different Vegetation Cover. Chinese Agricultural Science Bulletin, 30(23), pp. 303-307. 
Xiong, S. W., 2013. Inversion Study of Winter Wheat Drought based on HJ Satellite Data. Nanjing University of Information Science \& Technology.

Yan, F., Qin, Z. H., Li, M. S. and Wang, Y. J., 2006a. Progress in Soil Moisture Estimation from Remote Sensing Data for Agricultural Drought Monitoring. Journal of Natural Disasters, 15 (6), pp. 114-121.

Yan, N., 2009. Drought Monitoring in Shaanxi Based on MODIS Land Products LST, NDVI and EVI. Shaanxi Normal University.

Zhang, F., 2008. Remote Sensing Monitoring of Drought in Shaanxi Province Based on MODIS. Shaanxi Normal University.

Zhang, H. W., Chen, H. L., Liu, Z. Y., 2012a. Construction and application of enhanced surface water content index based on MODIS data. Meteorological Science and Techology, 40(6), pp. 1039-1043.

Zhang, J., Wu, J. J., Zhou, L., Lei, T. J., Liu, M., 2012a. Comprative Study on Remotely Sensed Methods of Monitoring Agricultural Drought Based on MODIS Data. Remote Sensing Information, 27(5), pp. 48-54.

Zhang, X. Y., Zhang, X. Y., Li, J. P., Shu, Z. .L, Cao, N., 2007a. Progress in Drought Monitoring by Remote Sensing in China. Meteorological Science and Techology, 27(5), pp. 48-54. 